\title{
Para a história do restauro de pintura em Portugal: as antigas intervenções no retrato de José António de Oliveira Machado, da Biblioteca Nacional de Portugal
}

\author{
António João Cruz y Carla Rego
}

Resumo: Uma pintura sobre tela, de finais do século XVIII, aparentemente em bom estado de conservação, mostrou que afinal já sofreu danos muito significativos, possivelmente devido às más condições de acondicionamento em que esteve. Na primeira metade do século XIX encontrava-se num depósito em Lisboa, para onde foram recolhidas as obras retiradas dos conventos, então extintos em Portugal. A pintura foi depois sujeita a numerosas intervenções de restauro, das quais as mais extensas foram tecnicamente bem executadas, provavelmente em finais do século XIX ou princípios do século XX, ainda que seguindo princípios diferentes dos actuais. Com base no estudo efectuado, recorrendo a diversos métodos de exame e análise, são descritas as intervenções detectadas, especialmente as operações de tratamento dos rasgões e de lacunas, algumas das quais executadas de forma pouco comum, assim como são identificados os materiais usados nessas intervenções.

Palavras-chave: história, restauro, pintura, tela, tratamento, rasgões, lacunas, reintegração cromática.

\section{To the history of painting restoration in Portugal: ancient interventions in the portrait of José Antó- nio de Oliveira Machado, from the National Library of Portugal}

\begin{abstract}
A canvas painting from the late 18th century, apparently in good condition, revealed that, after all, had already suffered considerable damage, possibly due to poor storage conditions. In first half of the 19th century, it remained in a storage at Lisbon, together with other works collected from the extinct Portuguese convents. The painting was then subjected to numerous restoration interventions, being the more extensive ones, technically well executed, probably in the late 19th or early 20th century, although under different principles from nowadays. Based on the study carried out and using various methods of examination and analysis, the restoration interventions are described, especially the treatments of tears and gaps, some of which were executed in a rather unusual manner. Materials used in these interventions, are also identified.
\end{abstract}

Key words: history, restoration, painting, canvas, treatment, tears, gaps, chromatic reintegration.

\section{Para la historia de la restauración de pintura en Portugal: las intervenciones antiguas en el retrato de José António de Oliveira Machado, de la Biblioteca Nacional de Portugal}

\footnotetext{
Resumen: Se presenta el estudio de una pintura sobre lienzo de finales del siglo XVIII, aparentemente en buenas condiciones pero que ha sufrido daños muy importantes, posiblemente debido a las malas condiciones del almacén de Lisboa donde fue trasladada en la primera mitad del siglo XIX junto con otras obras de los conventos entonces desamortizados en Portugal. La pintura fue sometida a numerosas intervenciones de restauración, las más extensas de las cuales fueron técnicamente bien ejecutadas, probablemente a finales del siglo XIX o principios del siglo $X X$, aunque de acuerdo con principios diferentes de los actuales. En base al estudio llevado a cabo utilizando diversos métodos de examen y análisis, se describen las intervenciones detectadas, especialmente las operaciones de tratamiento de desgarros y de lagunas, algunas de las cuales fueran ejecutadas de una forma inusual, y se identifican los materiales utilizados en estas intervenciones.
}

Palabras clave: historia, restauración, pintura, lienzo, tratamiento, desgarros, lagunas, reintegración cromática. 


\section{Introdução}

A pintura do espólio da Biblioteca Nacional de Portugal que representa o magistrado e desembargador José António de Oliveira Machado (1696-1777) [figura 1], com 84 cm altura por $64 \mathrm{~cm}$ de largura, é de autoria desconhecida, mas deve ter sido realizada entre 1750 e 1786 e incorporada na actual colecção em 1837 (Rodrigues 2013). Trata-se de uma obra sobre tela com as habituais características gerais, de natureza técnica e material, de uma pintura a óleo do século XVIII, tal como é sugerido quer pela observação directa da mesma, quer pelos resultados obtidos ao longo deste estudo.

À primeira vista, a obra parece estar em bom estado de conservação e não aparenta ter sofrido danos significativos nem ter sido alvo de significativas intervenções de restauro. Contudo, uma observação detalhada da sua superfície, além de evidenciar a habitual rede de estalados, característica de uma pintura antiga, permite concluir que já foi objecto de importantes intervenções de restauro que, no entanto, não estão documentadas. Considerando-se que há registo das intervenções recentes realizadas nas obras desta colecção, a sua ausência neste caso sugere que os restauros a que esta pintura foi sujeita são relativamente antigos.

Com o objectivo de contribuir para a história do restauro de pintura em Portugal, procedeu-se a um estudo que pretendeu identificar tais restauros, perceber a que problemas pretenderam responder, como foram executados, em que princípios se basearam e de que forma condicionaram a obra física e a imagem que hoje observamos. Para o efeito, a pintura foi deslocada para o Laboratório de Conservação e Restauro de Pintura de Cavalete e Escultura em Madeira Policromada do Instituto Politécnico de Tomar.

\section{Métodos de exame e análise}

Além da observação da pintura com lupa binocular (Leica M320) e da realização de fotografia com radiação visível (normal, luz rasante e pormenores), foram efectuados diversos exames e análises mais específicos.

Fotografias de infravermelho e de fluorescência de ultravioleta foram realizadas com câmara digital Mamiya 645AFDII com Back digital Phase One P21+ com filtro Lee 87, no primeiro caso, e filtro Lee 1B UV Absorber da LeeFilters e filtros de correcção de cor CC50M e CC30Y, no segundo caso.

A radiografia foi efectuada com ampola Art-Gil, tensão de $34 \mathrm{kV}$, intensidade de corrente de $5 \mathrm{~mA}, 1 \mathrm{~min}$ de exposição e película Kodak Industrex AA 400.

Foram recolhidas 15 amostras, que se pretendeu que contivessem todas as camadas, as quais, depois de montadas em resina acrílica e polidas, foram analisadas com microscópio óptico Olympus $\mathrm{CH} 30$ equipado com máquina fotográfica
Olympus DP10. As mesmas amostras, após recobrimento com filme de carbono, foram também analisadas com microscópio electrónico de varrimento Hitachi $3700 \mathrm{~N}$ com detector de raios $\mathrm{X}$ dispersivo de energia Bruker XFlash 5010 SDD usando tensão de 20 kV e intensidade de corrente de entre 110 e $125 \mu \mathrm{A}$.

Amostras de fibras foram analisadas por microscopia óptica e por recurso aos reagentes Herzberg e Lofton-Merrit. Para a análise das amostras do adesivo utilizado na reentelagem foram obtidos espectros de infravermelho num espectrómetro de infravermelho com transformada de Fourier Bruker Alpha com módulo de reflexão total atenuada com cristal de diamante.

\section{Estado geral da pintura e intervenções realizadas}

Os exames realizados, nomeadamente a radiografia [figura 2], a fotografia de ultravioleta [figura 3] e a fotografia de infravermelho, mostraram claramente que, não obstante o aparente bom estado em que se encontra a pintura, a obra já sofreu importantes danos e foi sujeita a numerosas operações de restauro. Do mais geral para o mais localizado, sem que seja seguida a ordem cronológica, podem-se destacar os seguintes acontecimentos em que a pintura esteve envolvida.

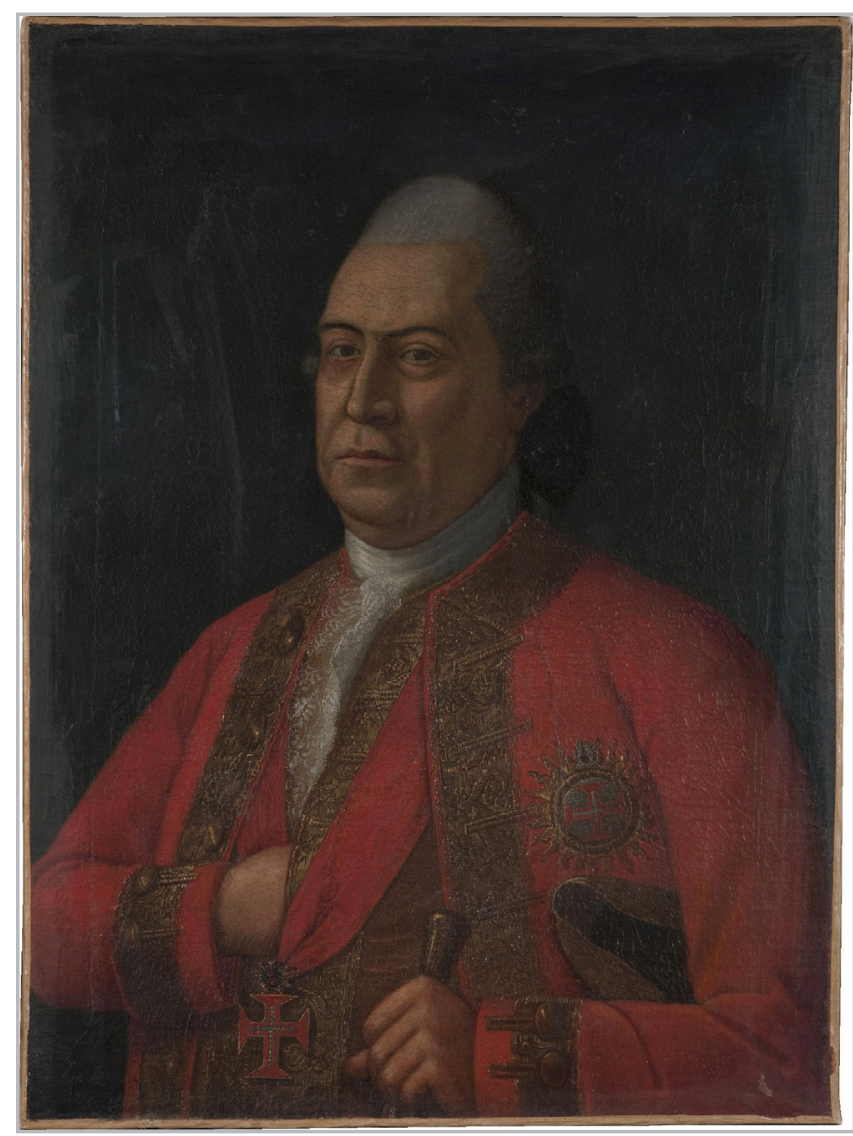

Figura 1. José António de Oliveira Machado, Biblioteca Nacional de Portugal, inv. 10943/BN. 
A pintura foi reentelada, não estando, portanto, directamente visível a tela original.

A grade actual, com aspecto relativamente recente, não é a original. Em primeiro lugar, porque se trata de uma grade extensível, com cunhas, ou seja, de um tipo que, mesmo em França, onde surgiu, só se tornou comum em finais do século XVIII (Buckley 2012). Em segundo lugar, porque a tela inicialmente estava numa grade com maiores dimensões e foi cortada. O corte ocorreu a toda volta, mas foi mais significativo do lado direito (do observador) uma vez que aí, ao contrário do que sucede dos outros lados, não se observa a deformação da tela devida à tensão originada pela fixação à grade (Van de Wetering 2000). Considerando o reduzido corte realizado em três dos lados e o facto de, como mostra a radiografia [figura 2], nos limites actuais do quadro haver a toda a volta uma faixa em que a pintura original se destacou, é possível que o corte não tenha sido realizado com o objectivo de alterar o formato, mas apenas para remover uma parte danificada da tela.

A tela sofreu extensos rasgões [figura 2 e figura 3]. O principal tem início no queixo do retratado e, devido a várias subdivisões da linha de ruptura, afecta grande parte da metade inferior da pintura. A irregularidade da linha e a sua orientação um pouco aleatória mas simultaneamente com troços mais ou menos rectilíneos sugerem que este rasgão resultou de acondicionamento incorrecto (Nicolaus 1999: 80). Tendo em conta as deficientes condições em que as pinturas estiveram, na década de 1840, no Depósito das Livrarias dos Extintos Conventos instalado no Convento de São Francisco (Soares et al. 2012a), parece muito provável que este rasgão tenha ocorrido então - ainda que o seu tratamento possa ter ocorrido muito mais tarde. Outro rasgão tem orientação vertical e aconteceu no lado esquerdo da pintura, defronte ao rosto junto ao limite interior da grade. Ainda que esta posição sugira que este segundo rasgão ocorreu depois de a tela ter sido colocada na actual grade, este não coincide exactamente com o limite da grade, podendo ter resultado do anterior engradamento. De qualquer forma, a linha de ruptura deste rasgão diferencia-se da do maior, uma vez que, no troço vertical, é muito menos irregular, quase sugerindo resultar de algo cortante [figura 2]. Há também rasgões de pequena dimensão, como um que se observa ao centro, na gola da casaca, podendo estes dever-se à perda de resistência da tela em resultado da oxidação da celulose (Nicolaus 1999: 82). Muito provavelmente, foram todos estes rasgões que estiveram na origem da reentelagem.

Além dos destacamentos já referidos, resultantes dos rasgões e do desgaste em todo o perímetro do quadro, a pintura sofreu outros pequenos destacamentos, principalmente na parte inferior, que poderão ter a mesma causa que o rasgão principal. De uma forma geral, as lacunas foram preenchidas com massas e reintegradas. Como adiante se explica, estes tratamentos ocorreram, no mínimo, em quatro ocasiões distintas - o que ajuda a explicar a sua distinta aparência, quer na radiografia [figura 2], quer na

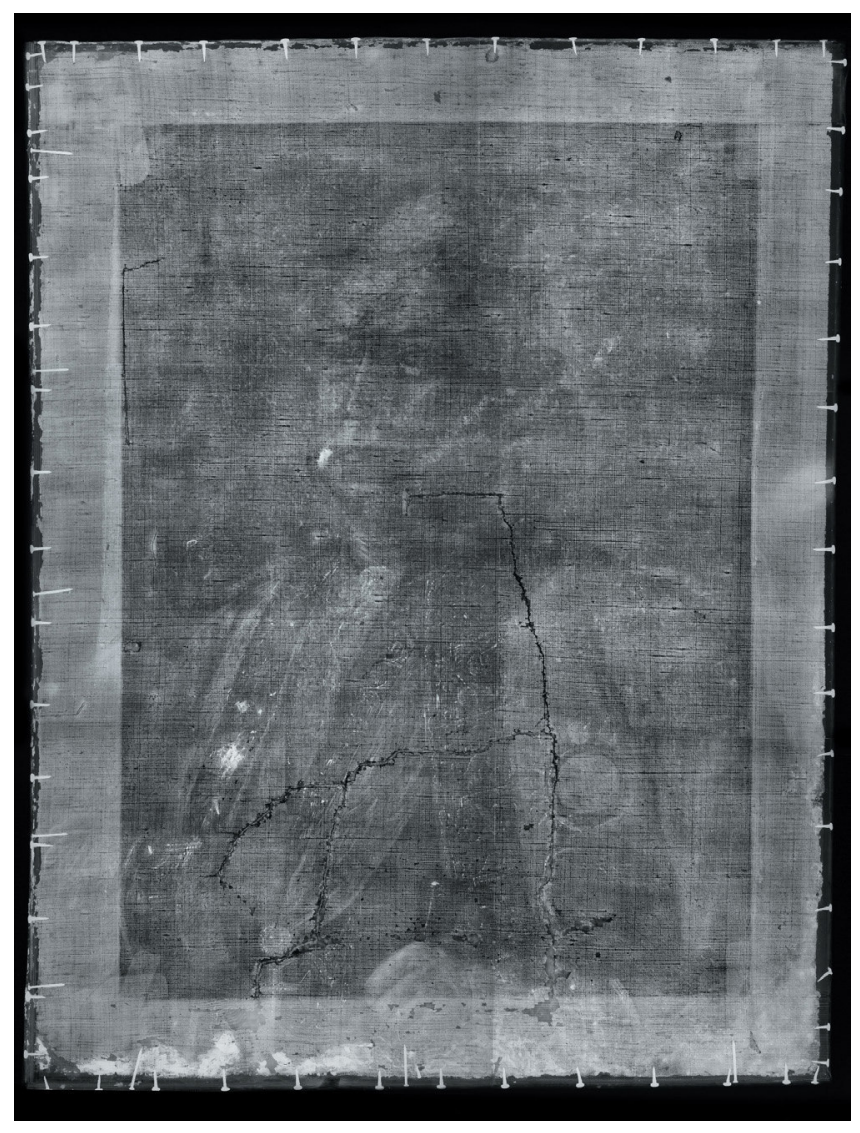

Figura 2. Radiografia.

fotografia de ultravioleta [figura 3]. Também o uso de dois tipos de pregos na fixação da tela à grade, como se observa na radiografia, é um testemunho de diferentes intervenções.

A fotografia de ultravioleta mostra também a existência de zonas repintadas, especialmente sobre os rasgões, rosto e quadrante inferior da pintura [figura 3].

\section{Tratamento dos rasgões}

Actualmente, a fragilidade do suporte original é colmatada pela suturação dos dois rasgões, cosidos directamente na tela de reentelagem que proporciona igualmente um reforço estrutural à pintura [figura 4]. De acordo com a identificação feita por microscopia óptica, a tela de reentelagem é de juta (quando a original é de linho) e o fio utilizado na sutura é de algodão. Segundo os espectros de infravermelho, a reentelagem foi feita com cola animal. A reentelagem seguida de suturação não parece ser um tratamento comum e, pelo menos num caso como este, só se justifica se o autor da intervenção tiver sérias dúvidas sobre a adesão entre as duas telas ou se pretender planificar o mais possível a pintura nas zonas de rasgão. Atendendo a que superfície da pintura se encontra bastante deformada junto aos dois rasgões principais [figura 5], é possível que tenha sido esta a razão da suturação, mas, se assim aconteceu, o sucesso foi limitado. Neste caso, a não 


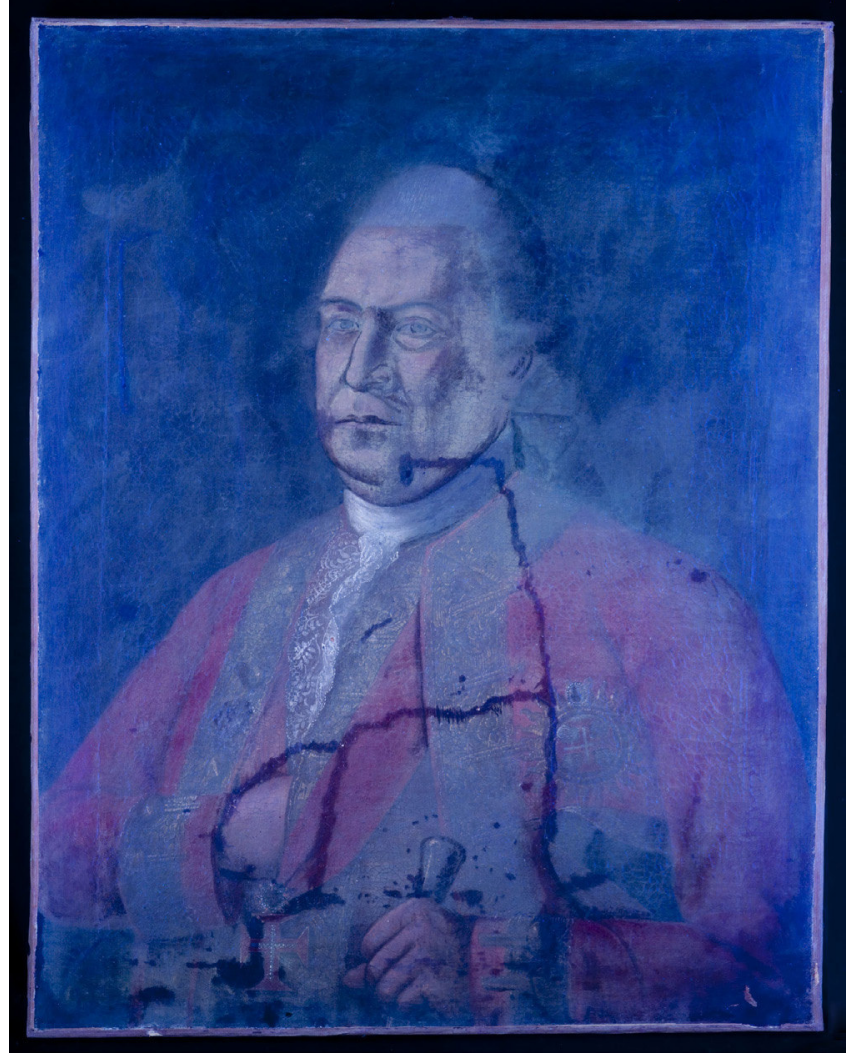

Figura 3. Fotografia de fluorescência de ultravioleta.

suturação dos rasgões de menor dimensão resultaria de a deformação nessas zonas não ser significativa.

Independentemente das razões que levaram a essa combinação da reentelagem com a suturação, a documentação obtida sugere que este não foi o primeiro tratamento dos rasgões. Nalguns troços mais ou menos horizontais do rasgão, na fotografia de ultravioleta observam-se pequenos traços perpendiculares à linha de ruptura, espaçados poucos milímetros, que parecem corresponder a pontos que mantêm junto os dois lados do rasgão, enquanto na radiografia se nota, de um lado e do outro da linha, o que parece corresponder a furos por onde passa, ou passava, a linha. Em qualquer um dos casos, o padrão observado nesses documentos é bem diferente do que se vê no reverso. Por outro lado, a radiografia mostra que foram usados dois materiais de preenchimento diferentes no rasgão principal: na metade superior um material muito pouco opaco aos raios $\mathrm{X}$ e nalgumas zonas da metade inferior (a começar no troço mais ou menos horizontal existente a meia altura) um material significativamente mais opaco. No rasgão do lado esquerdo, junto à grade, há também zonas de diferente opacidade. O uso com a mesma função, no mesmo rasgão, de dois materiais diferentes - os quais, como a seguir se refere, foram identificados numa amostra - sugere duas intervenções diferentes, a segunda das quais realizada numa ocasião em que o primeiro tratamento já não cumpria a sua função. Considerando que o branco de zinco, um material que ainda em 1859 era considerado um "produto novo e quasi

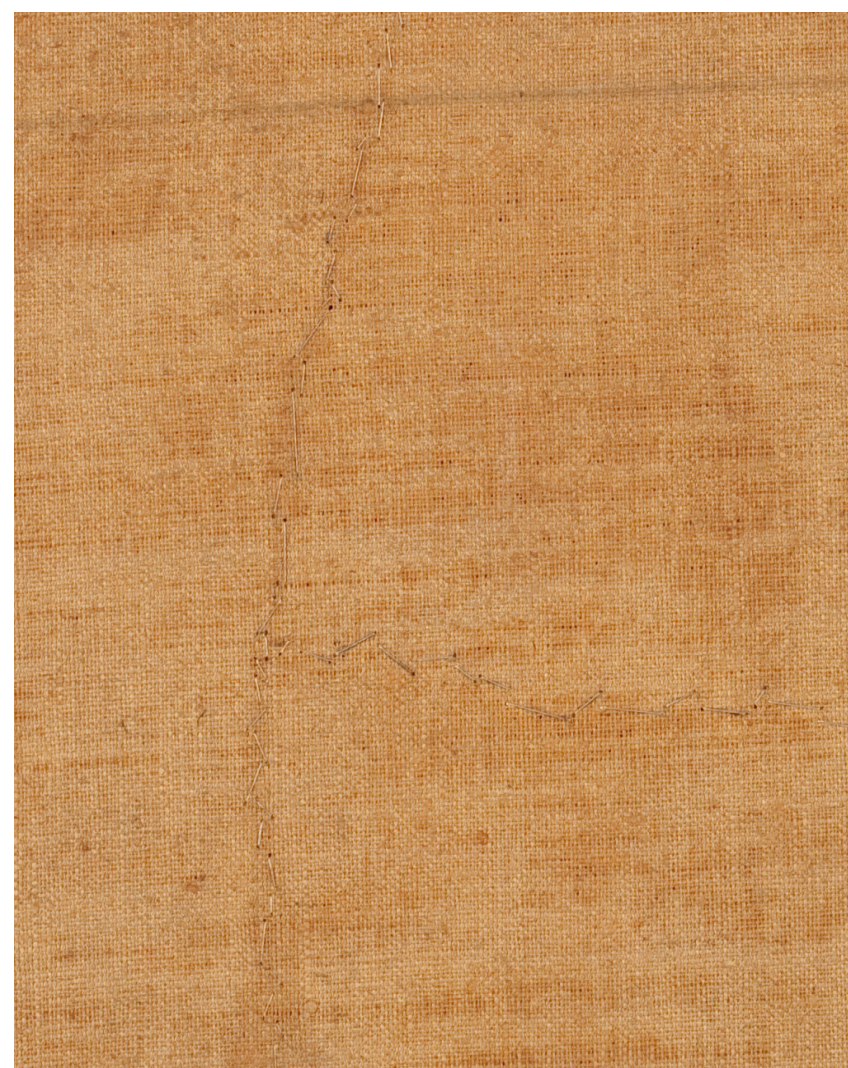

Figura 4. Sutura visível no reverso.

desconhecido no nosso paiz" (Santos 2012: 285), é um dos constituintes da massa de preenchimento usada nessa segunda intervenção, é muito pouco provável que esta seja anterior a finais do século XIX.

A suturação de um rasgão não parece ser um tratamento frequente em Portugal no final do século XIX ou início do século XX. Manuel Macedo, que era conservador do museu que esteve na origem do Museu Nacional de Arte Antiga, no único manual de restauro de pinturas então publicado, recomendava a planificação dos bordos do rasgão com ferro e a colagem da junta com cola animal (grude) (Macedo 1885). Outros tratamentos, visíveis nalgumas obras (Maltieira et al. 2013), envolviam o uso de remendos, que, porém, Macedo criticava severamente e que, por outro lado, veio a ser recomendado como processo geral para o tratamento de rasgões por um manual elaborado com o objectivo de servir de referência a nível internacional (International Museums Office 1940). Um terceiro tipo de tratamento de telas danificadas era a reentelagem, o qual, possivelmente, foi o mais comum em Portugal durante grande parte do século XX (Couto 1952), aliás como parece que aconteceu por todo o lado (Hackney et al. 2012). Portanto, o tratamento envolvendo a combinação da reentelagem com a suturação, observado na pintura em estudo, parece não ser comum e, eventualmente, poderá vir a ser considerado como marca identificativa de uma oficina de restauro. De qualquer forma, testemunha a diversidade de abordagens que têm sido seguidas nas intervenções de restauro em Portugal. 


\section{Tratamento das lacunas}

As lacunas resultantes dos rasgões foram preenchidas com uma massa de cor branca, ainda que a camada de preparação original tenha uma cor bem mais escu$\mathrm{ra}$, sendo constituída por mistura muito heterogénea, sobretudo, de branco de chumbo, ocre castanho com elevado teor de argilas e cré, aplicada em dois estratos que se diferenciam, entre outros aspectos, pelo teor de cré significativamente mais elevado no estrato superior. Nesta pintura, portanto, não foi seguida a prática que parece ter sido comum no passado de usar uma massa de preenchimento com luminosidade semelhante à do material da preparação original (Fuster-López 2012).

Essa massa de preenchimento de cor branca usada nos rasgões, no entanto, foi diferente nas duas intervenções referidas. A distinção é especialmente evidente numa amostra recolhida na zona do rasgão lateral, uma vez que nela se observam, sobrepostos, os dois materiais [figura 6]. De acordo com os resultados obtidos por microscopia electrónica de varrimento, a camada inferior, portanto a da intervenção mais antiga, é constituída essencialmente por cré (carbonato de cálcio), surgindo menos opaca na radiografia, enquanto a da intervenção mais recente, que, como já se referiu, não deve ser anterior a finais do século XIX, é constituída por uma mistura de cré com branco de zinco (óxido de zinco) em concen-

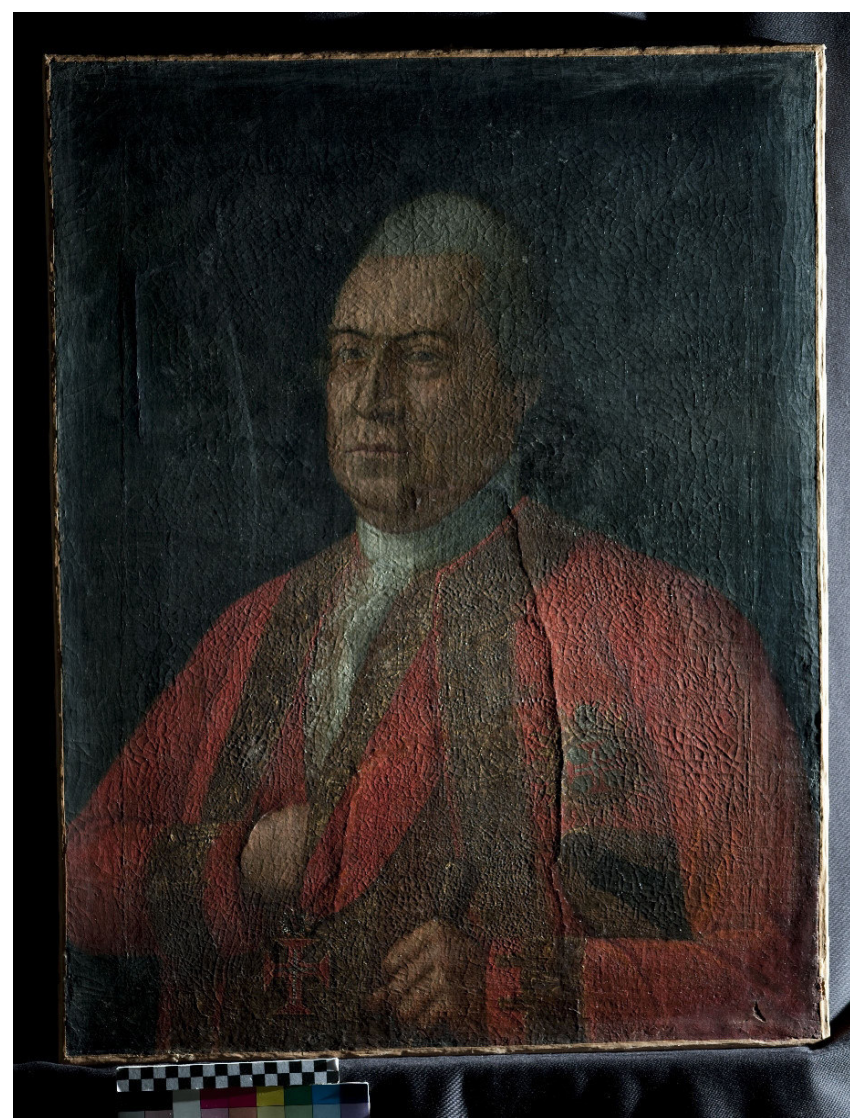

Figura 5. Fotografia de luz rasante. trações idênticas. Estas camadas foram identificadas em diversas outras amostras, embora não simultaneamente como neste caso.

O branco de zinco, ainda que em mistura, não parece ter sido habitualmente usado com esta função, mas a situação era diferente no que respeita ao cré. Noutras regiões, este com frequência era empregue nas massas de preenchimento (Fuster-López 2012) e, segundo Macedo (que o refere sob o nome de alvaiade de Espanha), era o material de preenchimento de lacunas geralmente utilizado em Portugal em finais do século XIX (Macedo 1885). O cré também era habitualmente usado dessa forma nas oficinas de restauro do Museu Nacional de Arte Antiga em 1940 (Albuquerque 2004) - e, provavelmente, quer antes quer depois dessa data. Curiosamente, o cré, que não era usado isoladamente como pigmento, fazia parte das listas de materiais a adquirir em $1864 \mathrm{e}$ em 1888 para o restauro de pinturas da mesma colecção a que pertencia a obra em estudo (Soares et al. 2012b).

Uma vez que não são evidentes sobreposições na radiografia, estas massas de preenchimento das lacunas parece circunscreverem-se às zonas de lacuna, tal como recomendava Luciano Freire no início do século XX (Cruz 2007). Por outro lado, deve notar-se que na segunda intervenção referida foram mantidas as massas anteriores - algo que, provavelmente, Macedo e Freire aprovariam (Cruz 2007), pelo que, de certa forma, se revela aqui também uma preocupação de minimizar a intervenção.

Os princípios seguidos no tratamento das lacunas resultantes dos rasgões não foram adoptados nas intervenções que incidiram especialmente na periferia da pintura, sobretudo no lado inferior, onde é possível detectar duas situações que, muito provavelmente, correspondem a duas intervenções diferentes.

Por um lado, algumas lacunas foram preenchidas com uma massa que, segundo uma das amostras recolhidas [figura 7], é constituída essencialmente por branco de chumbo (carbonato básico de chumbo) misturado com pequena concentração de um composto de cálcio. Esta massa é responsável pelas manchas de elevada opacidade que se observam sobretudo no canto inferior esquerdo da radiografia [figura 2]. Ao contrário das outras, não ficou limitada às zonas de lacuna, sobrepondo-se significativamente à camada cromática original, conforme se observa na referida amostra, onde se sobrepõe aos estratos castanhos e vermelhos originais que assentam na camada original de preparação. Portanto, este material é de uma intervenção muito menos cuidada do que as duas já referidas e deve ter ocorrido depois destas, pois de outra forma provavelmente teria sido removido.

Por outro lado, há diversas lacunas que não foram preenchidas, tendo sido reintegradas cromaticamente a um nível inferior [figura 8]. Evidentemente, correspondem a zonas de menor opacidade na radiografia e, das quatro 

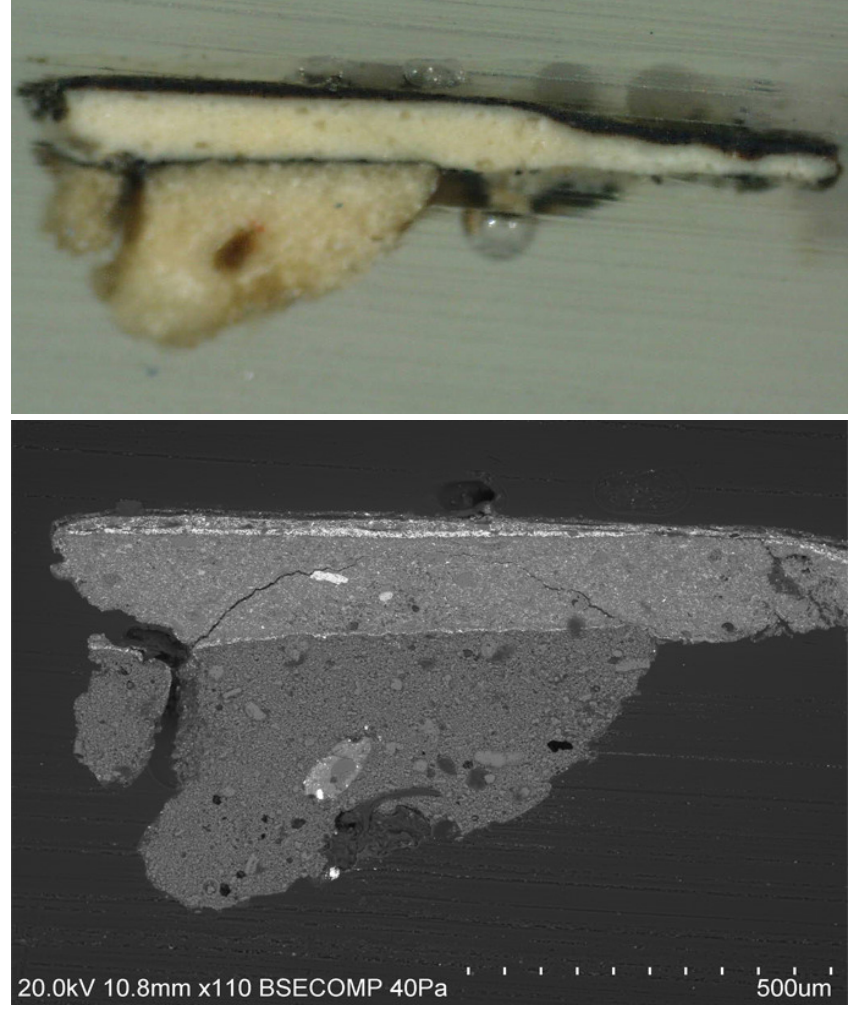

Figura 6. Amostra recolhida na zona do rasgão à esquerda: microscopia óptica e imagem de electrões retrodifundidos (microscópio electrónico de varrimento).

intervenções identificadas, deverá ser a mais recente - pois, se tivesse sido realizada antes da mencionada imediatamente atrás, as lacunas muito provavelmente teriam sido preenchidas com a massa à base de branco de chumbo. Desconhece-se, contudo se essa minimização da intervenção resultou de um princípio de conservação ou se simplesmente foi uma forma expedita de resolver a descontinuidade visual causada pelas lacunas.

\section{Reintegração cromática e repintes}

A reintegração cromática das lacunas foi efectuada de uma forma ilusionista, de modo a disfarçar o mais possível os danos que a pintura sofreu. Durante muito tempo este era o procedimento adoptado, afirmando-se claramente na segunda metade do século XIX que nas zonas em falta de um quadro deviam ser aplicadas as "novas tintas com tal esmero e arte, que sem alterar as tintas originais, haja tal homogeneidade de tons, que apenas deixe, mesmo a homens inteligentes, a dúvida se foi ou não restaurado" (Rodrigues 1875: 326). Ainda que no início do século XX o restaurador Luciano Freire manifestasse a opinião de que devia ser possível distinguir entre a matéria original e a matéria acrescentada pelo restaurador, mas sem prejudicar o efeito do conjunto (Cruz 2007), a tradição anterior manteve-se durante muito tempo e em meados do século $X X$ ainda a prática habitual no Museu Nacional de Arte Antiga era a de esses retoques serem "feitos de tal sorte que inteiramente se ajustem com as cores antigas e circundantes" (Couto 1952).

Segundo os resultados obtidos por microscopia electrónica de varrimento, a reintegração cromática efectuada após a aplicação das massas de preenchimento mais antigas, isto é, as massas constituídas essencialmente por cré, foi realizada através da aplicação de estratos cromáticos, por vezes muito finos, em que geralmente estão misturados diversos pigmentos. Estes pigmentos em grande parte fazem parte da lista de materiais recomendados para o restauro de pinturas em finais do século XIX (Macedo 1885): branco de chumbo (identificado através do $\mathrm{Pb}$ ), negro animal (P), vermelhão (Hg e S), amarelo de Nápoles (Sb e $\mathrm{Pb}$ ), ocre (Fe, Si e Al) e azul de cobalto (Co e Al). No entanto, foram igualmente utilizados outros pigmentos: o viridian $(\mathrm{Cr})$, que também não coloca problemas de conservação, e o amarelo de zinco ( $Z n$ e Cr na proporção atómica de, aproximadamente, 1:1), que tem tendência a escurecer por acção da luz (Eastaugh et al. 2004). Este, de todos os pigmentos referidos, é o menos comum. É um pigmento moderno, mas já era conhecido em Portugal em meados do século XIX (Santos 2012). No caso de alguns pigmentos, foram usa-

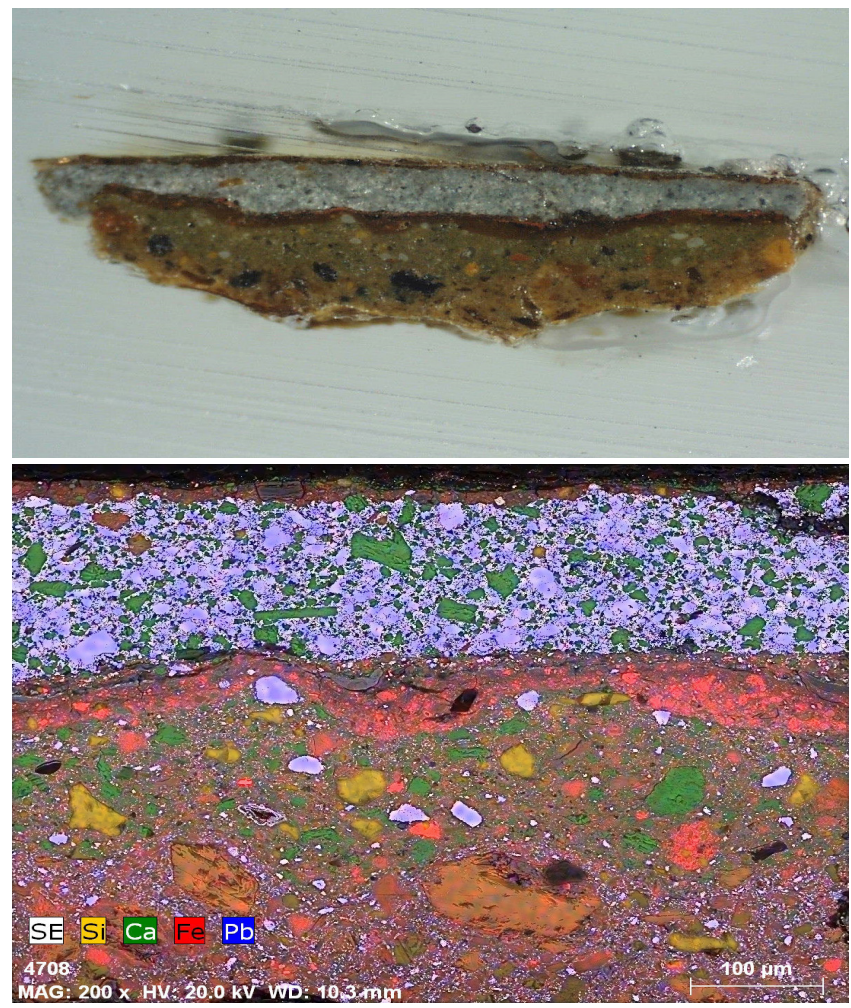

Figura 7. Amostra recolhida junto ao limite inferior da pintura, na zona acastanha da decoração da casaca: microscopia óptica e imagem do microscópio electrónico de varrimento, da parte superior da amostra, com mapa de distribuição de diferentes elementos químicos - entre os quais o chumbo (assinalado a azul), que surge concentrado na camada de cor branca. 


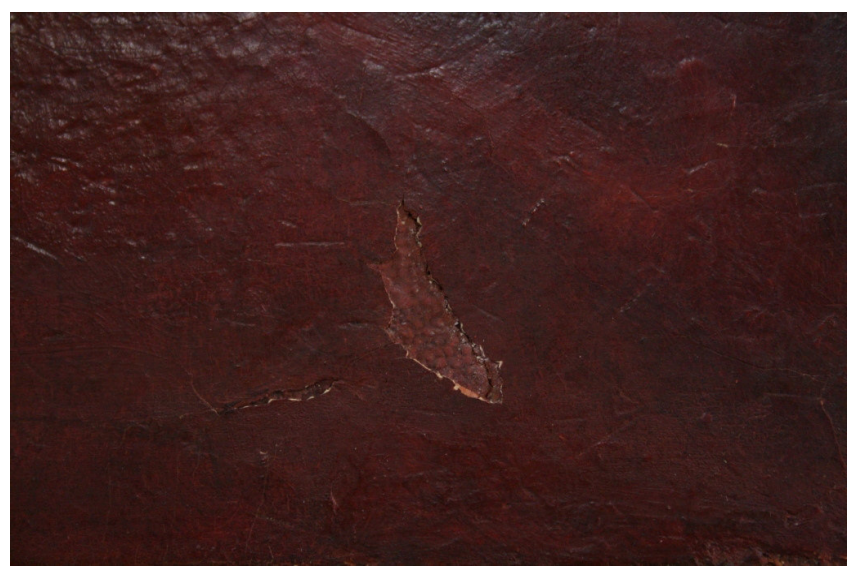

Figura 8. Lacuna de grande dimensão no canto inferior direito.

dos materiais de menor qualidade, uma vez que com frequência se detectou a presença de branco de bário (Ba e S) - um pigmento que é usado como carga, isto é misturado com outros, para os tornar mais económicos.

Estes pigmentos mostram que o restaurador não se limitava a usar os materiais tradicionais e que, por outro lado, os materiais disponíveis tinham algumas limitações em termos de qualidade ou que o restaurador não tinha especiais preocupações a esse respeito algo que parece ser pouco provável tendo em conta o cuidado na sua execução.

Na intervenção seguinte que foi efectuada nos rasgões, em que foi utilizada uma mistura de cré (identificado através do Ca na ausência de S) com branco de zinco (Zn) como massa de preenchimento, também foram empregues branco de chumbo $(\mathrm{Pb})$, negro animal $(\mathrm{P})$, vermelhão (Hg e S), ocre (Fe, Si e Al) e azul de cobalto (Co e Al) - por vezes igualmente com carga de branco de bário (Ba e S). Foi ainda usado o vermelho de Marte (Fe, estando ausente Si e Al).

Da intervenção mais localizada que incidiu na zona inferior da pintura e que é responsável pelas manchas de maior opacidade aos raios $X$, apenas se dispôs de uma amostra [figura 7]. Na camada superficial dessa amostra, com cor castanha, foi usada uma mistura de ocre castanho (Fe, Si, Al), negro animal $(P)$ e um pouco de vermelhão (Hg e S) — por um lado, pigmentos usados nas outras intervenções, mas, por outro lado, pigmentos que são dos mais comuns.

Numa das amostras que corresponde ao preenchimento mais antigo dos rasgões, a camada cromática da reintegração não assenta directamente na massa de preenchimento, mas entre as duas existe uma camada de material orgânico com cerca de $2 \mu \mathrm{m}$ que deve ter função de isolamento [figura 9]. Uma camada com semelhante composição, mas bastante mais espessa (20 $\mu \mathrm{m})$, foi observada noutra amostra, mas directamente sobre a camada original de preparação. Se resultam de uma mesma intervenção, não é possível saber com os dados disponíveis. No que diz respeito aos pigmentos usados nas camadas cromáticas de repinte colocadas sobre essas camadas orgânicas, além de pigmentos já mencionados (branco de chumbo, negro animal, ocre e, como carga, branco de bário), foram detectados branco de titânio ( $\mathrm{Ti}$ ), amarelo de crómio $(\mathrm{Cr}$ e $\mathrm{Pb})$ e, com a função de carga, uma argila (possivelmente caulinite, devido a razão atómica Si:Al de, aproximadamente, 1:1). Os repintes efectuados com branco de titânio não poderão ser anteriores a cerca de 1920, quando teve início a sua comercialização (Eastaugh et al. 2004), e, provavelmente foram realizados significativamente depois, uma vez que há sempre um lapso de tempo importante até que um pigmento se torne conhecido e usado por artistas (Santos 2012) - algo que é previsível que também se verifique entre restauradores.

Noutras amostras, de uma forma esporádica e em posição muito superficial, foram ainda detectados vermeIho de cádmio ( $\mathrm{Cd}, \mathrm{S}$ e $\mathrm{Se}$ ) e litopone de amarelo de cádmio ( $\mathrm{Ba}, \mathrm{Cd}, \mathrm{S}, \mathrm{Se}$ ) — sendo que aquele ficou disponível no comércio em 1910 e o segundo foi objecto de patente em 1921 (Eastaugh et al. 2004). Atendendo a essa localização e ao facto de essas amostras terem sido recolhidas em zonas de menor fluorescência de ultravioleta, esses dois pigmentos deverão ser de repintes relativamente recentes, ainda que não documentados.

\section{Conclusão}

O retrato de José António de Oliveira Machado, como muitas outras pinturas, aparenta estar em relativamente bom estado de conservação, mas o estudo realizado mostrou que no passado foi sujeito a diversas intervenções de restauro, algumas bastante importantes. As mais significativas, ainda que seguindo princípios ilusionistas diferentes dos princípios actualmente adoptados, parece terem sido executadas de forma minimamente cuidada, contrariamente a outras encontradas na obra.

Os danos que motivaram estas intervenções mais extensas suportam a hipótese de esta pintura ter entrado no Depósito das Livrarias dos Extintos Conventos, caso em que mostram as más condições de acondicionamento a que as obras foram sujeitas.

No que diz respeito ao conhecimento dos processos de restauro no passado, sobre os quais ainda há muito por saber, os procedimentos e materiais aqui detectados dão conta de uma diversidade de situações. Os resultados obtidos poderão ser úteis no futuro para a identificação dos tratamentos de restauro noutras obras e para o conhecimento da história material das mesmas. No entanto, o estudo das intervenções parece ser mais difícil do que o estudo dos materiais e das técnicas usadas na obra original, pois os materiais das intervenções 

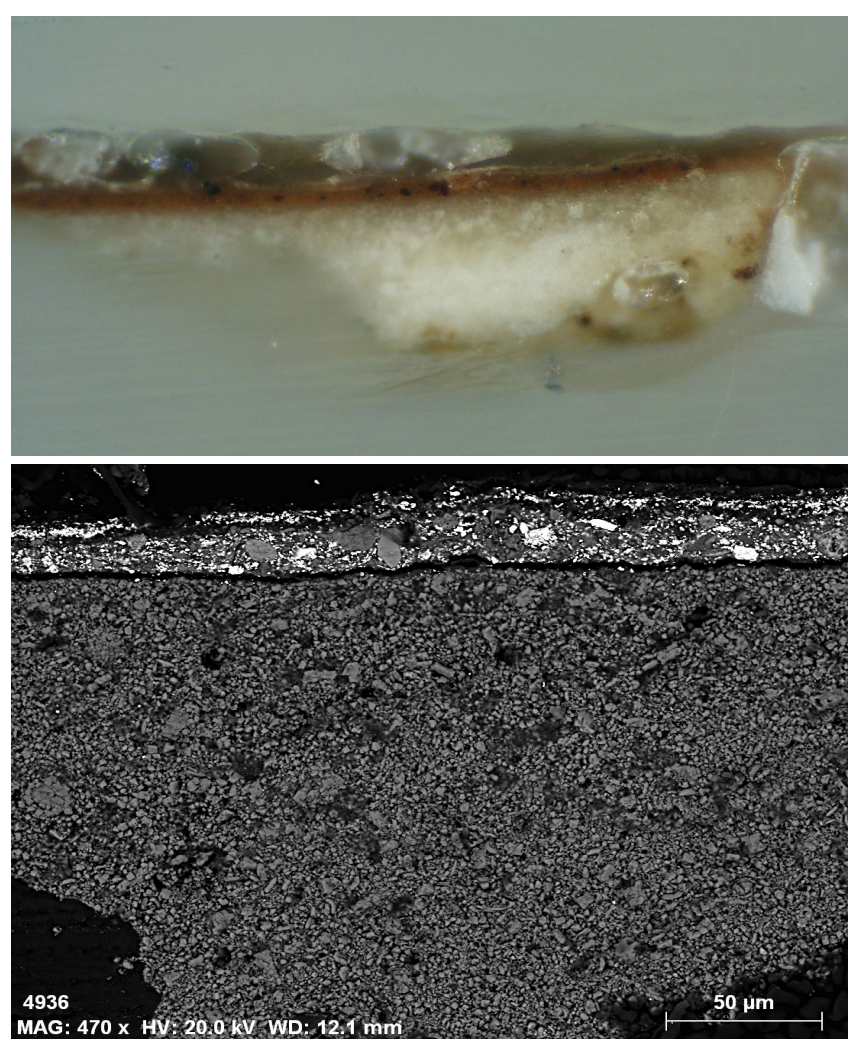

Figura 9. Amostra recolhida na mão, junto ao punho do bastão: microscopia óptica e imagem de electrões retrodifundidos (microscópio electrónico de varrimento) onde, no topo da camada espessa da massa de preenchimento, se observa uma fina camada escura que corresponde a material orgânico, sobre a qual se encontra a camada avermelhada da carnação.

não só se revelam através de uma forma fragmentada como com facilidade vão sendo substituídos ou afectados durante as intervenções subsequentes.

\section{Agradecimentos}

Agradece-se à Biblioteca Nacional de Portugal, em especial à sua actual directora, Maria Inês Cordeiro, e a Teresa Lança Ruivo, todo o apoio que tornou possível este estudo; a Gonçalo Figueiredo (IPT) as fotografias com iluminação normal, de luz rasante, de infravermeIho e de ultravioleta; a Vítor Gaspar (IPT) a radiografia e a identificação das fibras; a Lígia Mateus e Andreia Pardal (IPT) a preparação das amostras e sua fotografia no microscópio óptico; e a António Candeias (Laboratório Hércules) as facilidades que permitiram a realização das análises através de microscopia electrónica de varrimento e espectroscopia de infravermelho. Finalmente, agradece-se à Fundação para a Ciência e Tecnologia o financiamento do projecto "Eneias - A colecção de pintura da Biblioteca Nacional de Portugal: do resgate do património artístico conventual na implantação do Liberalismo ao estudo integrado de conservação e divulgação" (PTDC/HIS-HEC/113226/2009), em que este estudo se integra.

\section{Referências}

ALBUQUERQUE, B. (2004). “Intervenção de conservação e restauro no Retábulo da Capela de Nossa Senhora da Consolação dos Alvins ou da Carreira", Tecnologia \& Qualidade, 50: 37-39.

BUCKLEY, B.A. (2012). "Stretchers, tensioning, and attachments". Em The Conservation of Easel Paintings, J.H. Stoner, R. Rushfield (coord.). Abingdon: Routledge, 148-160.

COUTO, J. (1952). "Aspectos actuais do problema do tratamento das pinturas", Boletim do Museu Nacional de Arte Antiga, 2(3): 3-23.

CRUZ, A.J. (2007). “Em busca da imagem original: Luciano Freire e a teoria e a prática do restauro de pintura em Portugal cerca de 1900", Conservar Património, 5: 67-83.

EASTAUGH, N., WALSH, V., CHAPLIN, T., et. al.(2004). The Pigment Compendium. A dictionary of historical pigments. Oxford: Elsevier Butterworth-Heinemann.

FUSTER-LÓPEZ, L. (2012). "Filling". Em The Conservation of Easel Paintings, J.H. Stoner, R. Rushfield (coord.). Abingdon: Routledge, 586-606.

HACKNEY, S., REIFSNYDER, J., MARVELDE, M.t., et. al. (2012). "Lining easel paintings". Em The Conservation of Easel Paintings, J.H. Stoner, R. Rushfield (coord.). Abingdon: Routledge, 415-452.

INTERNATIONAL MUSEUMS OFFICE (1940). Manual on the Conservation of Paintings. Paris: International Institute of Intellectual Cooperation.

MACEDO, M. (1885). Restauração de Quadros e Gravuras. Lisboa: David Corazzi, Editor.

MALTIEIRA, R., CALVO, A., CUNHA, J. (2013). "A tela como suporte na exuberância do espaço arquitectónico português. Seu valor histórico, técnico e material como elemento essencial na estratégia de conservação". Em VIII Jornadas de Arte e Ciência, GVe Sousa, E Vieira (coord.). Porto: Escola das Artes da Universidade Católica Portuguesa, 194-205.

NICOLAUS, K. (1999). Manual de Restauración de Cuadros. Köln: Könemann.

RODRIGUES, F.A. (1875). Diccionario Technico e Historico de Pintura, Esculptura, Architectura e Gravura. Lisboa: Imprensa Nacional.

RODRIGUES, R.M. (2013). Comunicação pessoal.

SANTOS, S.B. (2012). Introdução e Circulação de Novos Materiais de Pintura em Portugal no Século XIX. Tese de doutoramento. Porto: Universidade Católica Portuguesa, Escola das Artes.

SOARES, C.M., RODRIGUES, R.M., CRUZ, A.J., et. al. (2012a). “Conservação e destruição de pinturas dos conventos extintos em Portugal durante o século XIX", ECR - Estudos de Conservação e Restauro, 4: 231-248. http://revistas.rcaap.pt/ecr/article/view/3095. 
SOARES, C.M., RODRIGUES, R.M., CRUZ, A.J., et. al.(2012b). "Historical and material approach to the paintings at the Portugal $\mathrm{Na}$ tional Library: contributions to the history of conservation and restoration of easel painting in the 19th century", International Journal of Heritage in the Digital Era, 1(S1): 283-288. http://dx.doi. org/10.1260/2047-4970.1.0.283.
VAN DE WETERING, E. (2000). Rembrandt. The Painter at Work. Berkeley-Los Angeles-London: University of California Press.

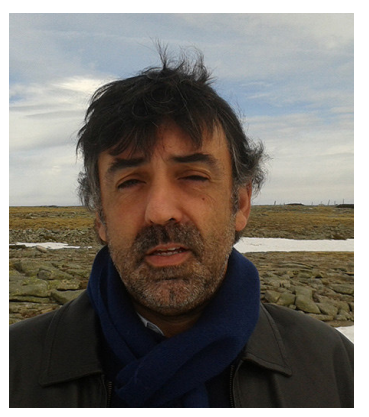

António João Cruz

ajccruz@gmail.com

Doutoramento em Química Analítica (Faculdade de Ciências da Universidade de Lisboa, 1993). Professor Adjunto e director do Mestrado em Conservação e Restauro da Escola Superior de Tecnologia de Tomar, do Instituto Politécnico de Tomar. Principais interesses: estudo laboratorial das obras de arte; tratados técnicos antigos relacionados com os materiais usados nas obras de arte; história dos materiais; história da conservação e restauro. Director da revista Conservar Património e membro da comissão científica e referee de diversas revistas nacionais e internacionais. E-mail: ajccruz@gmail.com.

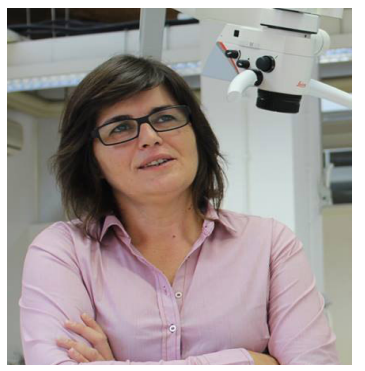

\section{Carla Rego}

cmrego@ipt.pt

Doutoranda em Investigación y Creación en Arte (Universidade do País Basco) e Mestre em Museologia e Património Cultural (Universidade de Coimbra, 2008). Docente de conservação e restauro de pintura e escultura na Escola Superior de Tecnologia de Tomar, do Instituto Politécnico de Tomar. Principais interesses: conservação e restauro de pintura (antiga e contemporânea) e escultura em madeira policromada; história da conservação e restauro; gestão de colecções; museologia. E-mail: cmrego@ipt.pt. 